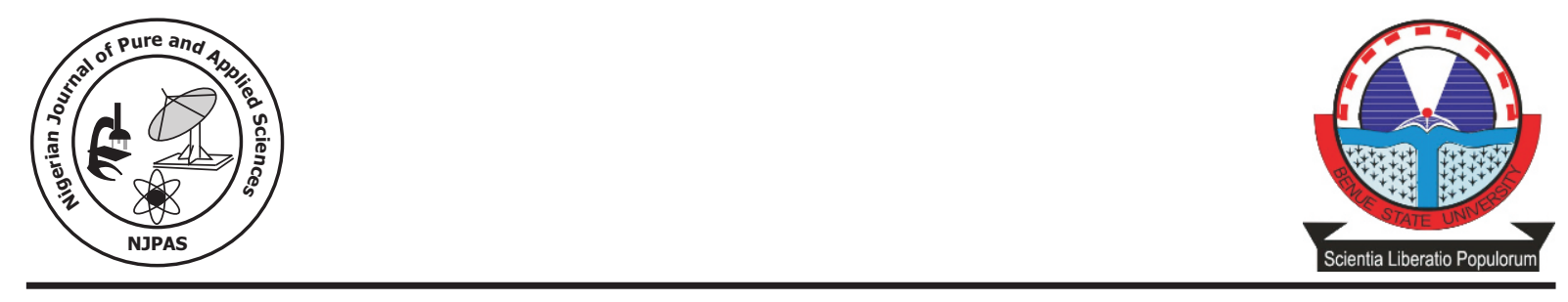

\title{
Investigation of Background Radiation Level Within X-ray Machine Environment
}

\author{
Gbaorun, F. and Terver, D. \\ Department of Physics, \\ Benue State University, Makurdi, Benue State.
}

\begin{abstract}
In this study, a Geiger Muller ionization counter has been used to investigate the variation of background radiation dose level with time in a typical $x$-ray machine room and its environment. This is to monitor the effect of $\mathrm{x}$-ray exposure on the background ionizing radiation level. The results showed that within a period of 3 hours, the cumulative background radiation dose in the $x$-ray room grew from an initial level of $38.78 \times 10^{-\mathrm{s}}$ Gy to around $84.90 \times 10^{-} \mathrm{Gy}$ compared with nearby rooms where the cumulative radiation grew from almost zero to a maximum value of about $46.9 \times 10^{-\mathrm{s}}$ Gy within the same period. It was observed that after a radiation exposure from the machine, the background radiation dose rate took about 25 minutes to decay from a maximum level of around $45 \times 10^{-s} \mathrm{~Gy} / \mathrm{hr}$ to the background level about $17.47 \times 10^{-s} \mathrm{~Gy} / \mathrm{hr}$ which was found to be higher than the background dose rates in other nearby locations. While the dose rate in the $x$-ray machine room was higher than the maximum dose limit of $12 \times 10^{-s} \mathrm{~Gy} / \mathrm{hr}$ recommended for members of the public by the International Committee for Radiation Protection (ICRP), the dose rates in the other locations studied in the neighbourhood of the $x$-ray machine were within the limit.
\end{abstract}

\section{Introduction}

Man in his environment, is constantly exposed to ionizing radiation from natural and artificial sources, Agba (2009). The natural sources include cosmic rays and radioisotopes from rocks, soil and air in the environment. However, it is known that radiation from radio-isotope disintegration contributes largely to the background ionizing radiation level in the environment. These radiations change the physical state of atoms, causing them to be electrically charged or ionized.

The most important artificial man-made sources of exposure are x-rays and radioisotopes used for medical diagnosis and treatment in hospitals. Exposure to x-rays causes ionization of the air in the environment. Salasinski (1982) and Omatsuli (2004) found that the ion concentration in a typical $\mathrm{x}$-ray room decays to the background level within 10 to 20 minutes of the exposure. In view of the harmful effects of the radiation, International Commission for Radiological Protection, ICRP (1991) recommended that medical exposure should be kept as low as reasonably possible, thus establishing the ALARA concept. This concept is aimed at minimizing the radiation doses given to patients and their escorts as well as radiographers who work in the radiation environment all through the year. Opening the doors to the x-ray room may however help in reducing the background ionization level in the direct environment of the $\mathrm{x}$-ray machine room, but this is likely to increase the 
background level in nearby units.

The hazards often associated with exposure to $\mathrm{x}$-rays include tissue cell mutation, risk of genetic effects as well as development of cancer tumors. Regular workers in the x-ray environment therefore wear protective lead aprons. Even with that, there is usually a fraction of the radiation that may penetrate the apron shield, apart from the fact that the entire body is not protected. This is why radiation badges are worn by radiation workers to make sure that their total cumulative radiation absorption per year will not be above the accepted level recommended by the World Health Organisation WHO (1965). It is therefore necessary to monitor from time to time the radiation exposure level in an x-ray machine room and its nearby environment.

In this study, we have investigated the background $\mathrm{x}$-ray exposure level in a typical $\mathrm{X}$-ray machine room and its immediate environment, and the result was compared with that of the external environment. The aim of this study is to measure the background radiation level in rooms and offices around a typical x-ray machine in order to investigate the effect of x-ray exposure on the background ionizing radiation level in the environment.

\section{Experimental Method}

Measurement of the background ionizing radiation levels were carried out in the Radiology department, Federal Medical Centre, Makurdi, Nigeria, using a Digilert 50 radiation Geiger Muller ionization counter, model inspector 06250 .

Four different measurement sites were chosen within the X-ray unit. The sites were: the $\mathrm{x}$-ray room, (room 1), the radiographer's office, (room 2), which was adjacent to the $\mathrm{x}$ ray room, the patient waiting room, (room 3 ), about 10 meters away and the immediate open field external environment, (room 4).

The radiation level in each location was measured by placing the ionization counter $1.0 \mathrm{~m}$ above the ground level and noting the amount of ionizations produced in the air. The choice of the height is influenced by the need to avoid the effect of other radiations such as rays of $\alpha$ - and $\beta$ terrestrials origin Salasinki (1982).

The Geiger Muller counter employed is capable of recording changes in the cumulative ionization count in air. This allows the determination of the variation of the cumulative adsorbed dose in air with time as well as the dose rate. During each day of measurement for five days, readings of the total ionization counts were taken every 20 minutes for a period of 3 hours between 10 a.m and 2 p.m and the variation of the cumulative absorbed dose and the dose rate were determined. Measurement were repeated five different times at each site and the mean characteristics dose distribution was obtained.

\section{Results}

In Tables 1 and 2, Room 1 represents Xray room, Room 2 is the Radiographer's office, Room 3 is the patients' waiting room and Room 4 represents the open field external environment. Figure 1 detailed in Table 1 shows the variation of the cumulative radiation dose with time over a period of 3 hours in the 4 different locations. It may be seen from the Figure that the background radiation dose in the $\mathrm{X}$-ray room started from an initial level of about

$38.78 \times 10^{-s}$ Gy and grew to about $84.90 \times 10^{-8} \quad$ Gy within 3 hours, whereas in the other 3 sites, the radiation level started from around zero and grew linearly to a maximum value of about $47 \times 10^{-\mathrm{s}}$ Gy The initial high level of the cumulative dose in the x-ray room was due to the large background radiation dose in the room. In addition the slope of the linear growth of the ionization in the room is higher than that of any the other sites. The distribution of the radiation dose is also higher in the radiographers' room than the adjacent patients' waiting room and the open field environment respectively.

Figure 2 detailed in Table 2 shows the variation of the X-ray dose rate measured in each of the experimental sites. The Figure shows that the radiation dose in the $\mathrm{x}$-ray room takes about 25 minutes to 
Table 1: Cumulative radiation dose with time over a period of $\mathbf{3}$ hou $\mathbf{r s}$ in the $\mathbf{4}$ different locations. Time (min) Cumulative dose $\times 10^{-s}$ (Gy)

\begin{tabular}{lllll}
\hline & Room 1 & Room 2 & Room 3 & Room 4 \\
20 & 38.78 & 0.00 & 0.00 & 0.00 \\
40 & 44.63 & 6.95 & 6.80 & 6.79 \\
60 & 50.32 & 12.00 & 10.90 & 10.80 \\
80 & 56.73 & 18.65 & 16.60 & 16.55 \\
100 & 62.50 & 24.80 & 22.75 & 21.95 \\
120 & 68.42 & 30.40 & 27.90 & 27.05 \\
140 & 74.31 & 36.50 & 32.80 & 31.70 \\
160 & 80.05 & 42.50 & 38.50 & 37.50 \\
180 & 84.90 & 46.90 & 44.00 & 43.80 \\
\hline
\end{tabular}

Table $\mathbf{2}$ : Variation of dose rate with time over a period of $\mathbf{3}$ hours in the $\mathbf{4}$ different locations . Time ( $\mathrm{min}$ ) dose Rate $\times 10^{-5}$ (Gy/hr)

\begin{tabular}{lllll}
\hline & Room 1 & Room 2 & Room 3 & Room 4 \\
\hline 20 & 45.00 & 17.61 & 13.32 & 14.32 \\
40 & 38.34 & 14.32 & 13.89 & 13.47 \\
60 & 17.07 & 15.46 & 12.56 & 10.63 \\
80 & 20.46 & 14.97 & 10.72 & 12.16 \\
100 & 19.07 & 15.00 & 11.77 & 08.97 \\
120 & 16.20 & 13.68 & 11.03 & 10.16 \\
140 & 17.47 & 14.03 & 12.85 & 11.73 \\
160 & 15.74 & 12.75 & 10.97 & 11.07 \\
180 & 13.78 & 12.00 & 11.00 & 10.92 \\
\hline
\end{tabular}
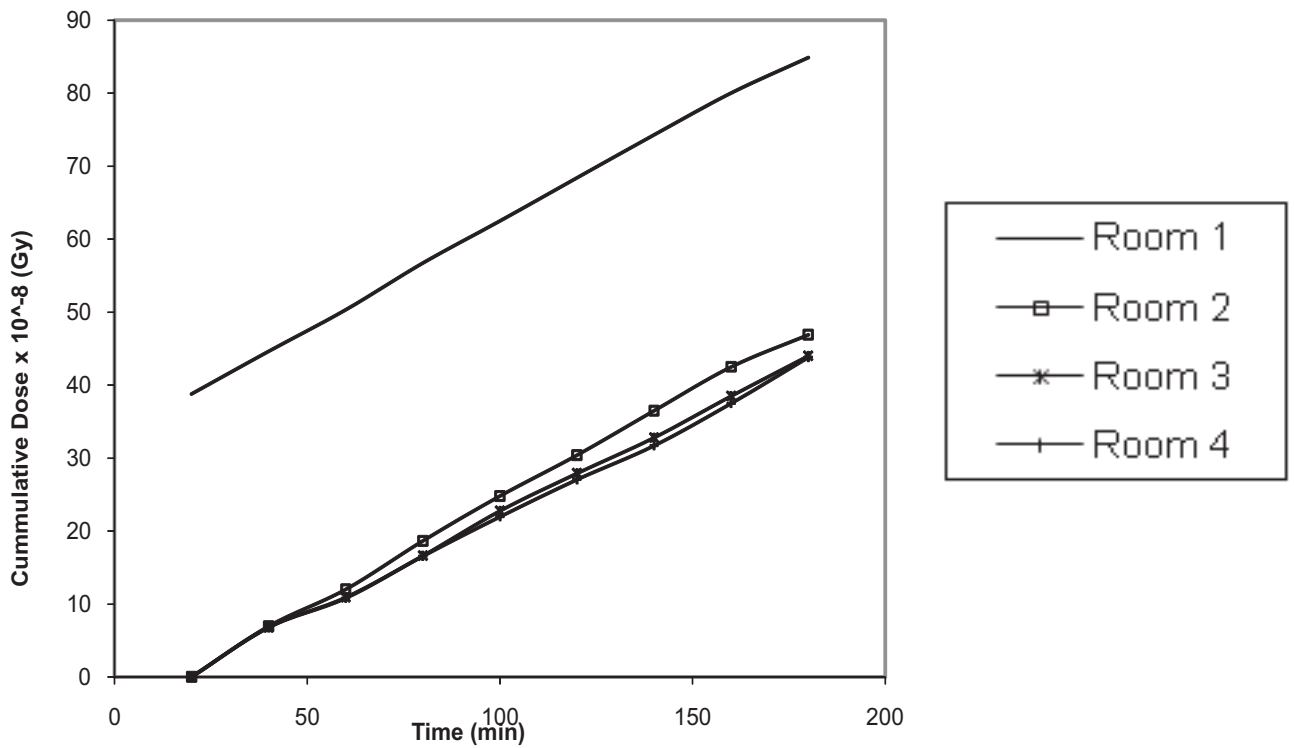

Fig. $1 \mathrm{Graph}$ of Cumulative dose against time. The values of cumulative dose are of the order X 10 decay from the maximum level of round

$45 \times 10^{-8} \mathrm{~Gy} / \mathrm{hr}$ after an exposure, to the background level of around $17.47 \times 10^{-8} \mathrm{~Gy} / \mathrm{hr}$. The dose rate in the radiographers room also oscillates around a mean of $14.42 \times 10^{-8} \mathrm{~Gy} / \mathrm{hr}$. in same vein, that of the patient's' waiting room was next with a mean of $12.01 \times 10^{-8} \mathrm{~Gy} / \mathrm{hr}$, while that of the open field environment is $11.49 \times 10^{-8} \mathrm{~Gy} / \mathrm{hr}$. It may be observed that the dose rate is largest in the $\mathrm{x}$-ray room, followed by the radiographers' room, the patients' waiting room and the open field environment.

The main contribution to the background radiation level in the x-ray room and the adjacent rooms may be attributed to the scattered radiation from the $x$-ray machine after each exposure. It may also be augmented by some level of gamma rays of terrestrial origin in the environment

The work of Ajayi and Laogun (2005) 
indicated that the radiation level in the largely to the level of atmospheric gamma and neighbouring open field can be attributed cosmic rays in the environment.

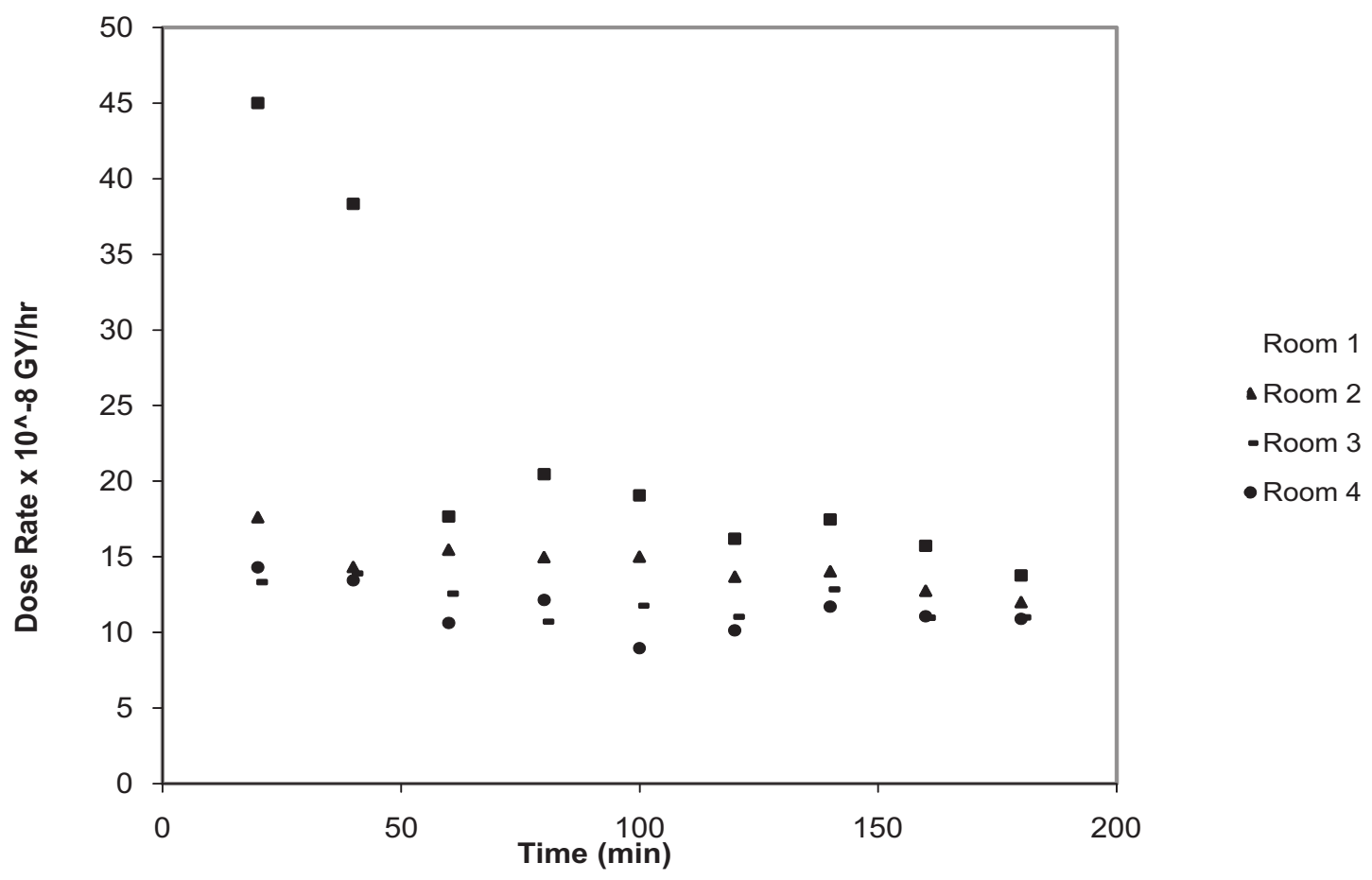

Fig. 2: Variation of the radiation dose rate with time

\section{Discussion}

Radiations in a variety of forms have familiar effects on man. As light is a radiation we can see, heat is one we can feel, while other kinds of radiations such as ultraviolet, gamma and $\mathrm{x}$-rays can neither be seen nor immediately felt. Such radiations have sufficient energies to produce electrically charged particles upon colliding with matter and are known as ionizing radiations. All individuals receive radiation from both natural and man-made sources which may include dose from x-ray machines in hospitals during diagnostic and therapeutic procedures. Occupational workers such as radiographers receive additional dose from the type of radiation work they do. Some typical interaction mechanisms of $\mathrm{x}$-rays with matter include Compton scattering, Photoelectric effect and pair production. When the photons interact with atomic electrons in air or in tissue, all or part of the energy is imparted to the electron. Energy not absorbed by the electron will be carried away to the next interaction site. Thus, $x$-ray photons in their passage through matter cause ionization of the atoms and so, over exposure to $\mathrm{x}$-rays especially in hospitals often results in a number of biological effects such as x-ray dermatitis and cancerous tumour formation Alexander (1966) and Blatz (1964). It is therefore necessary to measure the scattered radiation levels in the diagnostic $\mathrm{x}$-ray environment in hospitals as it forms an important parameter often needed in determining the radiation protection requirement for the design of an $\mathrm{x}$-ray room.

From the results obtained in this study, it may be said that the high level of radiation in the $\mathrm{x}$-ray room is largely due to stay photons from the $x$-ray machine. According to the Beer Lambert radiation law (9) given by:

$$
I=I_{o} e^{-\mu x}
$$

where $\mu_{\text {is the energy absorption coefficient of }}$ the medium and $\mathrm{x}$ is the distance of propagation, the intensity of the radiation of propagation, the intensity of the radiation decreases exponentially with distance. The radiation in the $\mathrm{x}$-ray room is therefore higher 
than those in the other rooms. Some distance away from the $\mathrm{x}$-ray machine. The radiographers, office is however closer to the $\mathrm{x}$-ray room than the other sites. The nearness accounts for the relatively higher radiation level than in other two measurement sites. In addition to this, the poor ventilation in the office may also contribute to the high radiation level

\section{Conclusion}

It is necessary to constantly measure the radiation level around an x-ray unit. Where the dose exceeds the safe limits will call for a review of work practice and equipment performance. Also low level radiation areas can be identified for use as administrative offices and patients' waiting room for irradiation so that the individuals may get the least possible dose.

The result of this work shows that in the $\mathrm{x}$-ray unit studied, there is an increased radiation level in the $\mathrm{x}$-ray machine room. The International Committee for Radiation ICRP(1977) recommended a maximum radiation safety limit of around $230 \times 10^{-8}$ and $120 \times 10^{-8} \mathrm{~Gy} / \mathrm{hr}$ for medical radiation workers and members of the public respectively. It may seem that our values of background dose rates in the x-ray and the radiographers' rooms are much lower than the dose rate recommended for medical radiation workers the levels are still higher than that for members of the public. On a more relaxed note, our dose values for the patients waiting room and the neighbouring field environment are not significantly different from the public. Finally, since the main principle of radiation protection is to keep all dose as low as reasonably achievable, we would recommended that adequate ventilation be provided for X-ray rooms so as to reduce the associated high background radiation levels.

\section{References}

Salasinnski, K. (1982). Air Ionization in radiotherapy rooms. International Journal of Biometeorology, 26(2):165167.

Omatsuli, M.F. (2004). Measurement of stray radiation around a diagnostic x-ray machine. MSc Thesis, University of Benin.

ICRP Report. (1977). Recommendations of the International commission on radiological Protection Publication 26 Oxford, U.K. Pergamon Press.

WHO Report. (1965). Public Health and Medical Use of Ionizing radiation. Technical report Series No.306 Geneva.

Lagaogun, A. A., Ajayi, N.O. and Agaja, S.A (2005). Variation levels at the Nigerian Petroleum Development Oil field Ologbo, Edo State, Nigeria. Nigerian Journal Physics, 5:1-6.

Ajayi, N.O. and Laogun, A.A. (2005). Influence of Vertical level. Nigerian Journal of Space Science, 2:9-13.

Alexander, P. (1966). Atomic radiation and life Penguin Books Incorporated, USA.

Blatz, H. (1964). Introduction to radiological health. McGraw-Hill Book Co. Inc Nig.

Brown, H.B., Smallwood, R.H.D. Barber, P.V. Lawford. and D.R. Hose, (1999). medical Physics and Biomedical Engineering. Ed. J.G. Webster. I.O.P Publishing, British. 